\title{
Article \\ Development of Folded Expanded Metal Mesh with Sound Absorption Performance
}

\author{
Jui-Yen Lin, Yaw-Shyan Tsay *(D) and Pin-Chieh Tseng
}

Department of Architecture, National Cheng Kung University, Tainan 70101, Taiwan;

N78031132@mail.ncku.edu.tw (J.-Y.L.); 10908061@mail.ncku.edu.tw (P.-C.T.)

* Correspondence: tsayys@mail.ncku.edu.tw; Tel.: +886-6-2757575 (ext. 54155)

check for updates

Citation: Lin, J.-Y.; Tsay, Y.-S.;

Tseng, P.-C. Development of Folded Expanded Metal Mesh with Sound Absorption Performance. Appl. Sci. 2021, 11, 7021. https://doi.org/ 10.3390/app11157021

Academic Editor: Giuseppe Lacidogna

Received: 16 July 2021

Accepted: 27 July 2021

Published: 29 July 2021

Publisher's Note: MDPI stays neutral with regard to jurisdictional claims in published maps and institutional affiliations.

Copyright: (c) 2021 by the authors. Licensee MDPI, Basel, Switzerland. This article is an open access article distributed under the terms and conditions of the Creative Commons Attribution (CC BY) license (https:/ / creativecommons.org/licenses/by/ $4.0 /)$.

\begin{abstract}
Reverberation time (RT) is an important factor affecting the quality of indoor acoustics. Using sound-absorbing materials is one method for quickly and effectively controlling RT, and installation in the ceiling is a common location. Sound-absorbing ceilings come in many forms, with light steel joist ceilings commonly used in office spaces, classrooms, and discussion rooms. Light steel joist ceilings are often matched with sound-absorbing materials such as gypsum board, mineral fiberboard, rock wool, and coated glass wool, but such materials may have durability and exfoliation problems. Therefore, considering performance and health, in this research, we aimed to design an expanded metal mesh (EMM) structure specimen for sound-absorption material, namely folded expanded metal mesh (FEMM). The results show that the FEMM can significantly improve the sound-absorption performance of the expanded metal mesh. The $\alpha_{w}$ of single panel is $0.05-0.35$, and the $\alpha_{w}$ of FEMM is $0.65-0.85$. On the other hand, the sound-absorption performance of the full frequency band has been significantly improved. Furthermore, the field validation result shows that RT decreased from $1.05-0.56 \mathrm{~s}$ at $500 \mathrm{~Hz}$, meanwhile, the sound pressure level (SPL) is still evenly distributed, and speech clarity $\left(C_{50}\right)$ is increased by $5.6-6.5$.
\end{abstract}

Keywords: folded expanded metal mesh; ceiling panels; room acoustics

\section{Introduction}

In acoustics, mastering reverberation time (RT) is an important item for creating a great indoor acoustic environment, and one of the common control methods is to use a soundabsorbing ceiling. However, many types of ceiling systems are currently available, light steel joist ceilings in particular are commonly used in such places as offices, classrooms, discussion rooms, etc. Common sound-absorbing materials used with light steel joist ceilings include gypsum board, mineral fiberboard, rock wool board, calcium silicate board, and covered glass wool, all of which perform well with sound-absorbing ability and are easy to obtain. However, these materials can become warped, deformed, grow fungus, or peel off and may even cause air pollution that affects the health of users due to various environments and times [1]. For solving this problem, Yang et al. [2] found that natural materials such as kapok fiber, pineapple-leaf fiber, and hemp fiber are ideal substitutes for traditional sound-absorbing materials, but as building materials, it is still necessary to notice a moisture resistance problem. Therefore, both performance and durability of the material should be considered in the design when using sound-absorbing materials.

Offices and classrooms are the most intensive spaces for intellectual and cognitive activities in daily life, so the indoor acoustic design of such spaces has become a popular research topic. Kaarlela-Tuomaala et al. [3] compared the acoustic differences between small offices and open-plan offices. When the acoustic environment has a negative impact, employees became distracted, and work efficiency decreased. Rachel and Roy [4] pointed out that $70 \%$ of causes for distracted employees in open office spaces are noise interference. Passero and Zannin [5] conducted a field measurement of indoor acoustics in an open 
office space, including sound pressure level, RT, and speech intelligibility, and their results showed that the separation between working seat panels and the installation of ceilings with high sound-absorbing capacity were necessary conditions for better acoustics. For the classroom, many studies have proposed that a comfortable acoustic environment is highly correlated with users' learning ability [6-8]. Ricciardi and Buratti pointed out that being in a noisy environment for a long time has a high correlation with the effect of speech $\left(\mathrm{R}^{2}=0.9\right)$, indicating that noise will seriously reduce learning ability [9].

In order to achieve full-band sound absorption, most products on the market are manufactured with a multi-layer structure, which contains more than two materials and in turn produces different sound-absorption performances. Such structures then create a wider sound-absorption band [10,11]; for instance, metal composite materials are often combined with filler material in ceilings [12-14].

In 1988, Maa [15] proposed a double-layer micro-perforated panel structure, which proved that the sound-absorption characteristics of the said structure were the same as the acoustic resonance structure of a single panel at high frequency, and an additional absorption peak appeared at middle-low frequency. Meanwhile, Maa also pointed out that pore size, perforation rate, thickness, and cavity of the panels affected the soundabsorption coefficient.

In recent years, more and more studies have discussed the multi-layer structure and the structure behind the micro-perforated panel. Meng et al. [16] used the sandwich board to carry out sound-absorption coefficient experiments for four specimens and found that the sound-absorption coefficient was effectively improved via the perforated panel. Jung et al. [17] proposed a multi-layer sound-absorption material of the micro-perforated panel that effectively increased the sound-absorption band and the coefficient. Other studies have proposed different shapes of structures in an attempt to increase the support capacity of the specimen while also improving the sound-absorption performance of the material. For instance, Yu et al. [18] proposed to add the concept of origami to the design of the sound barrier. Meanwhile, Wang et al. [19] disassembled a multi-layer structure of the folding panel into multiple units of Helmholtz resonance to calculate the sound-absorption coefficient. However, the manufacturing costs of micro-perforated panels are considerably higher than other materials.

Regarding the shape of the cavity in a sound-absorbing structure, some studies have pointed out that an incomplete cavity could effectively improve sound-absorption performance $[11,20,21]$. Furthermore, after an unshaped cavity structure is divided into several independent cavities, the results show that the low-frequency sound-absorption ability was improved [22-24]. Meanwhile, the multi-layer structure with a folding panel has been used as a support structure for the surface panel.

Expanded metal mesh (EMM) is very different from the common perforated metal plate. In the manufacturing process, EMM is formed by equidistant slitting and stretching, which can reduce material waste. In addition, the tiny holes on the EMM plate generate the potential for sound-absorbing.

In this study, we focused on the acoustic resonance structure of the metal panel based on the manufacturing cost; therefore, the object in this study is EMM with a lower cost. In order to obtain higher sound-absorbing performance while considering the structure of the material, this research proposed sound-absorption structures composed of EMM based on the height of the specimen, the thickness of the cavity, and the folded shape, followed by the development of the folded expanded metal mesh (FEMM). Furthermore, we used the light steel joist ceiling of an office as the application target. After installing the FEMM with better sound-absorption performance in the space, we then carried out field verification.

\section{Folded Expanded Metal Mesh (FEMM) Development and Prototyping}

This research was divided into two stages: laboratory measurement and field verification. In the first stage, we analyzed the basic sound-absorption performance of the specimen and then separately discussed the sound-absorption performance of a single 
panel and folded structure. In the second stage, the developed product was installed in an office to perform indoor acoustic measurements.

\subsection{Specimens}

EMM was selected as the development object for this research. Figure 1 shows the panel surface of EMM and the arrangement of the holes, and the wavy recesses of the surface are produced during the manufacturing process, and the waves likely provide the sound-absorption effect. This research shows that different specimen structures have been designed to develop a FEMM with high sound-absorption performance as the purpose. Therefore, by discussing different specimen sizes and cavity depths, we were able to propose specimen structures and analyze the influence of each structure on sound-absorbing performance, as shown in Figure 2.

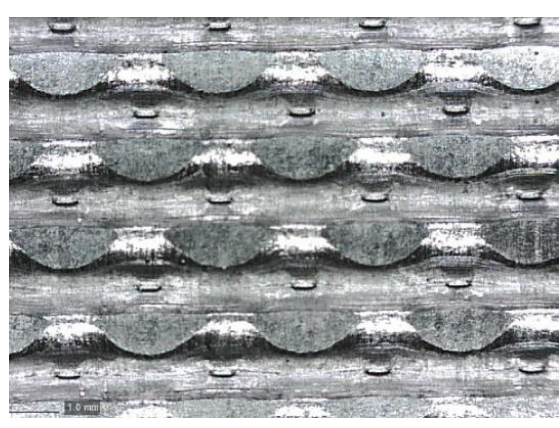

(a)

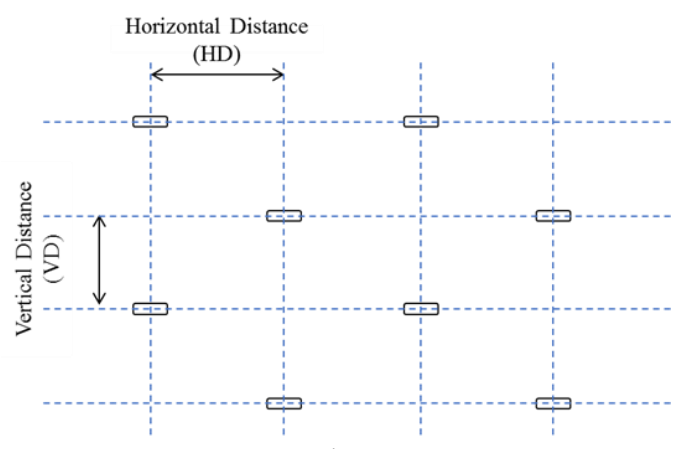

(b)

Figure 1. The expanded metal mesh (EMM): (a) the surface texture of the EMM; and (b) the perforation diagram of the EMM.

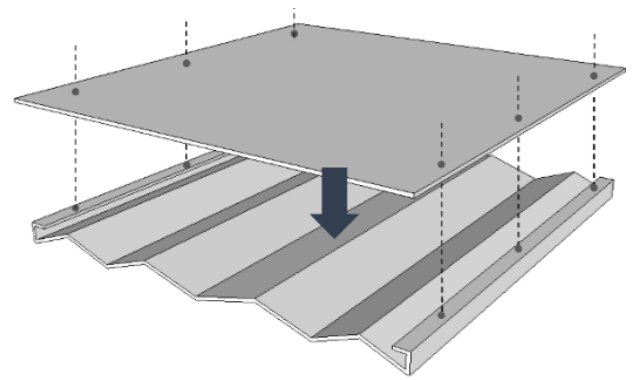

(a)

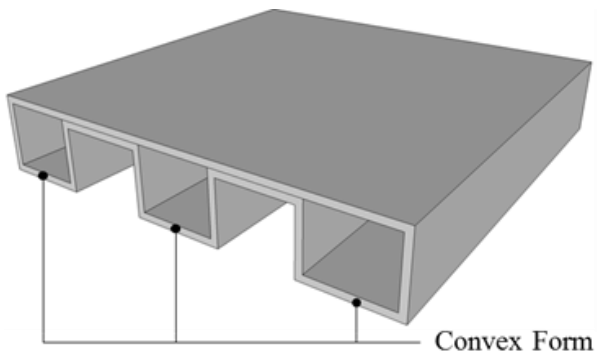

(c)

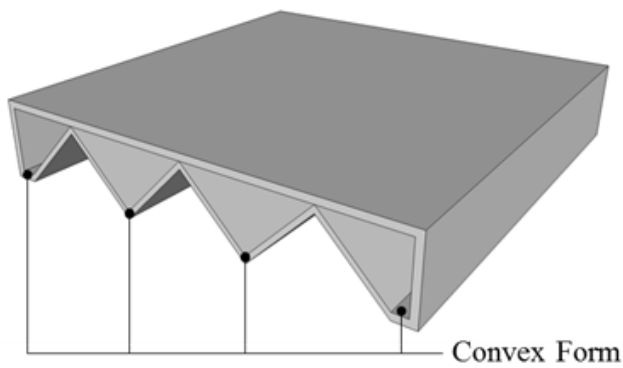

(b)

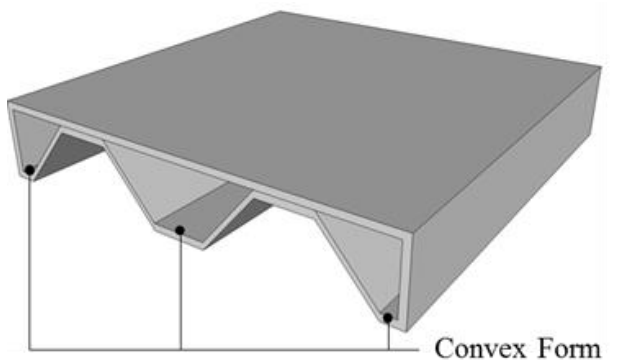

(d)

Figure 2. Folded expanded metal mesh (FEMM) diagrams: (a) the built-up construction of FEMM; (b) the triangular structure of FEMM; (c) the rectangular structure with three convex forms of FEMM; and (d) the trapezoidal structure with three convex forms of FEMM.

In the first part, we used four different types of EMM to confirm the basic soundabsorption performance, which measured 12 sets, and the size of each EMM was $750 \mathrm{~mm} \times 900 \mathrm{~mm}$. The second part adopted one type of EMM from the first part for 
extended development. However, since this research was aimed at light steel joist ceilings, considering structural strength and size, we proposed $600 \mathrm{~mm} \times 600 \mathrm{~mm}$ of each piece of FEMM with different structures and carried out 30 sets of sound-absorption performance measurements. Figures 3 and 4 show the installation method of specimens in the laboratory.

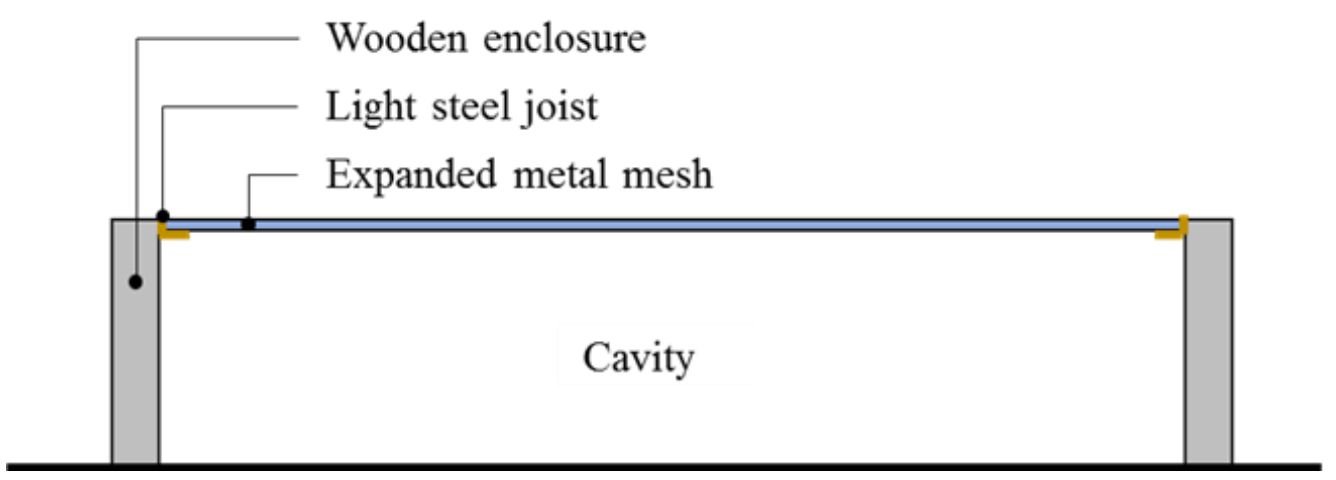

Figure 3. Diagram of the single-panel specimen in the laboratory.

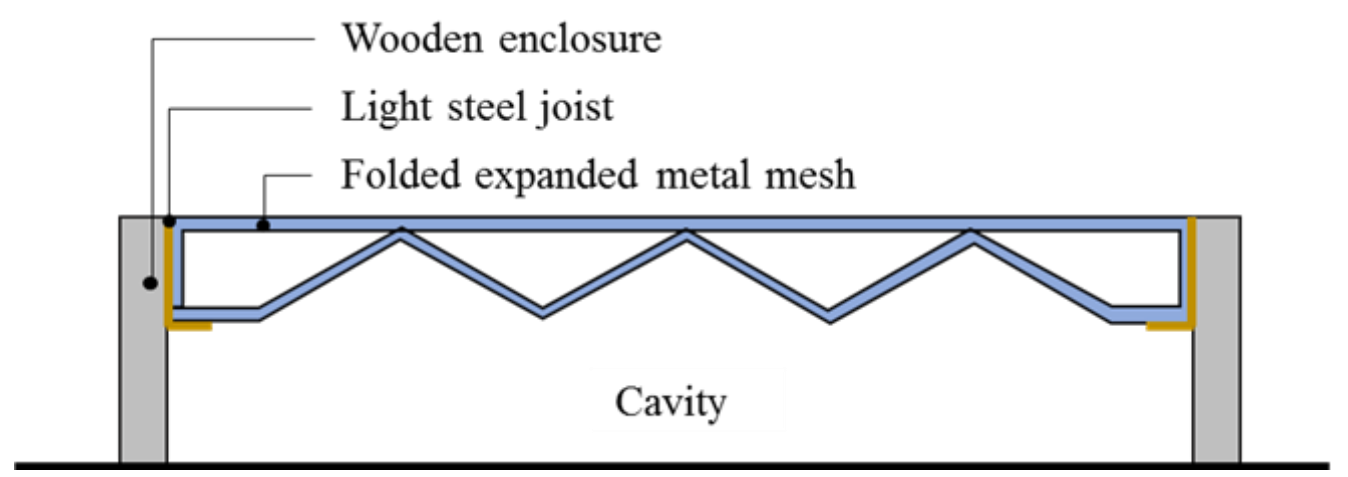

Figure 4. Diagram of the FEMM specimen in the laboratory.

\subsection{Experiments}

In this study, we measured the sound-absorption coefficient pursuant to the ISO 354 regulation [25], and the value was carried out according to the sound-absorption rating in ISO 11654 [26], and we measured six points and recorded the temperature and humidity before and after the introduction of the specimen. The volume of the reverberation room was $171.3 \mathrm{~m}^{3}$, its surface area was $184.3 \mathrm{~m}^{2}$, and its floor area was $32.8 \mathrm{~m}^{2}$. The laboratory features a floating structure to reduce outside interference in the experiment. The total area of the test specimen was $10.8 \mathrm{~m}^{2}(3 \mathrm{~m} \times 3.6 \mathrm{~m})$, and it was placed at the center of the floor. The calculation of the sound absorption coefficient are shown in Equation (1), as shown in Figure 5.

$$
\alpha_{s}=55.3 \times V\left(\frac{1}{c_{2} T_{2}}-\frac{1}{c_{1} T_{1}}\right)-4 V\left(m_{2}-m_{1}\right)
$$

where $V$ is the volume of the empty reverberation room $\left(\mathrm{m}^{3}\right) ; c_{1}$ is the propagation speed of sound in air at the temperature $T_{1}(\mathrm{~m} / \mathrm{s}) ; c_{2}$ is the propagation speed of sound in air at the temperature $T_{2}(\mathrm{~m} / \mathrm{s}) ; T_{1}$ is the reverberation time of the empty reverberation room (s); $T_{2}$ is the reverberation time of the reverberation room after the test specimen has been introduced (s); and $m_{1}$ and $m_{2}$ are the power attenuation coefficients $\left(m^{-1}\right)$. 


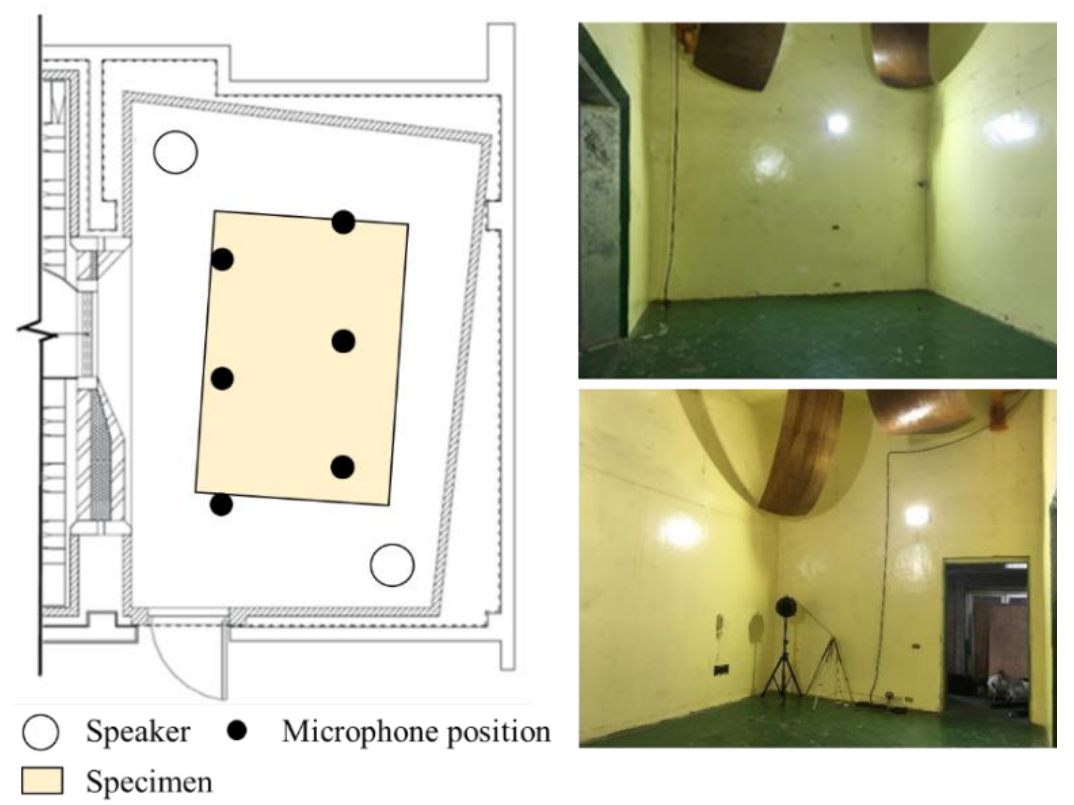

Figure 5. The installed position of the specimen in the reverberation room.

\section{Measurement Results}

\subsection{The Single-Panel Structure}

Table 1 shows the EMM of four single panels that are divided into two different board thicknesses and the distance of the hole, with three different cavities (Type A to Type D). We tested and analyzed the sound-absorption performance of EMM of 12 specimens.

Table 1. The specimen setting and measurement results of expanded metal mesh (EMM).

\begin{tabular}{|c|c|c|c|c|c|}
\hline \multirow[b]{2}{*}{ No. } & \multicolumn{2}{|c|}{ Arrangement of the Holes } & \multirow{2}{*}{$\begin{array}{l}\text { Panel Thickness } \\
\text { (mm) }\end{array}$} & \multirow{2}{*}{$\begin{array}{l}\text { Cavity } \\
(\mathrm{mm})\end{array}$} & \multirow[b]{2}{*}{$\alpha_{w}$} \\
\hline & $\begin{array}{l}\text { Horizontal Distance } \\
(\mathrm{mm})\end{array}$ & $\begin{array}{l}\text { Vertical Distance } \\
(\mathrm{mm})\end{array}$ & & & \\
\hline A1 & \multirow{3}{*}{1} & \multirow{3}{*}{2} & \multirow{3}{*}{0.5} & 210 & 0.30 \\
\hline A2 & & & & 260 & 0.30 \\
\hline A3 & & & & 460 & 0.30 \\
\hline B1 & \multirow{3}{*}{2} & \multirow{3}{*}{4} & \multirow{3}{*}{0.5} & 210 & 0.05 \\
\hline B2 & & & & 260 & 0.05 \\
\hline B3 & & & & 460 & 0.10 \\
\hline $\mathrm{C} 1$ & \multirow{3}{*}{1} & \multirow{3}{*}{2} & \multirow{3}{*}{0.6} & 210 & 0.35 \\
\hline $\mathrm{C} 2$ & & & & 260 & 0.35 \\
\hline $\mathrm{C} 3$ & & & & 460 & 0.35 \\
\hline D1 & \multirow{3}{*}{2} & \multirow{3}{*}{4} & \multirow{3}{*}{0.6} & 210 & 0.20 \\
\hline D2 & & & & 260 & 0.20 \\
\hline D3 & & & & 460 & 0.15 \\
\hline
\end{tabular}

The arrangement of the holes had a significant effect on sound-absorption performance when compared to the thickness of the board. Figures 6-8 show that increasing the thickness of the cavity mainly improves low-frequency sound-absorption performance. Furthermore, comparing the results of different EMM with the same cavity thickness showed the same trend in the sound-absorption coefficient curve. However, different cavity thicknesses had no significant effect on the weighted sound-absorption coefficient $\left(\alpha_{w}\right)$, as shown in Table 1. 


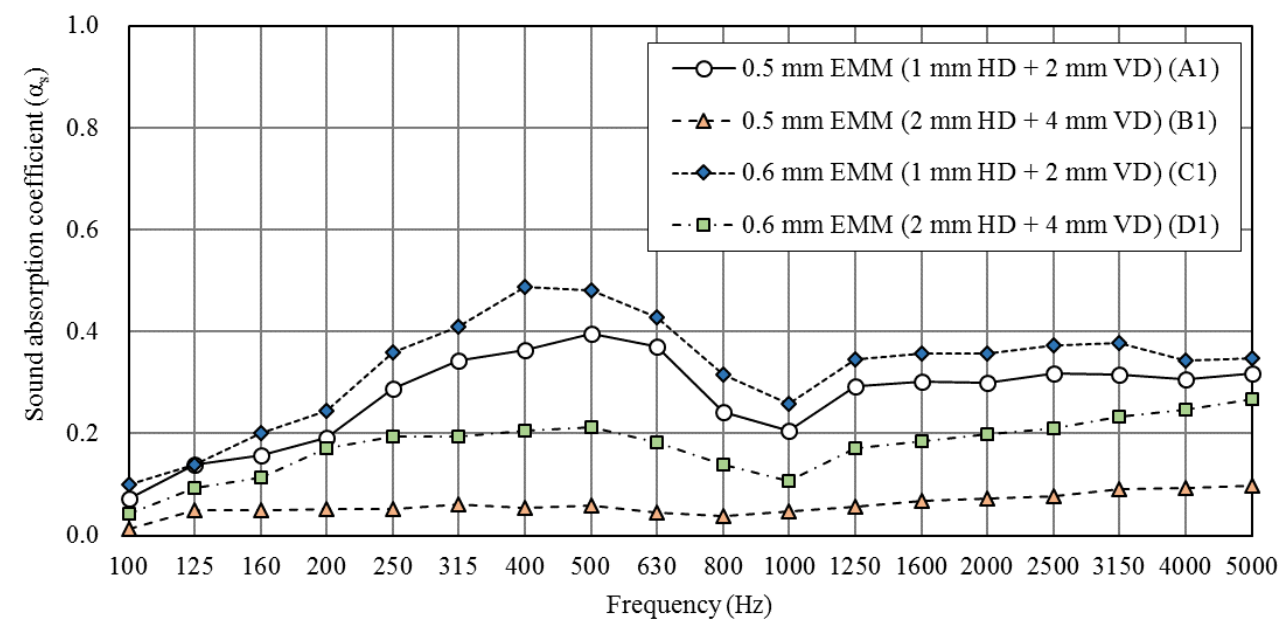

Figure 6. The sound-absorption coefficient of EMM with a $210 \mathrm{~mm}$ cavity.

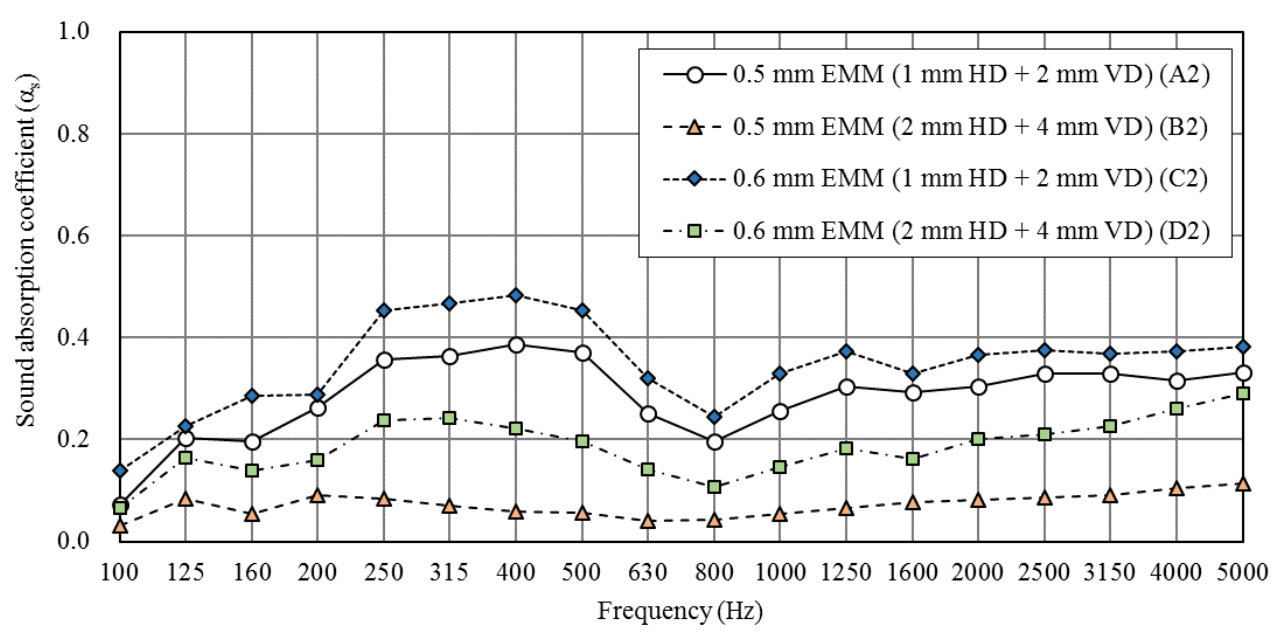

Figure 7. The sound-absorption coefficient of EMM with a $260 \mathrm{~mm}$ cavity.

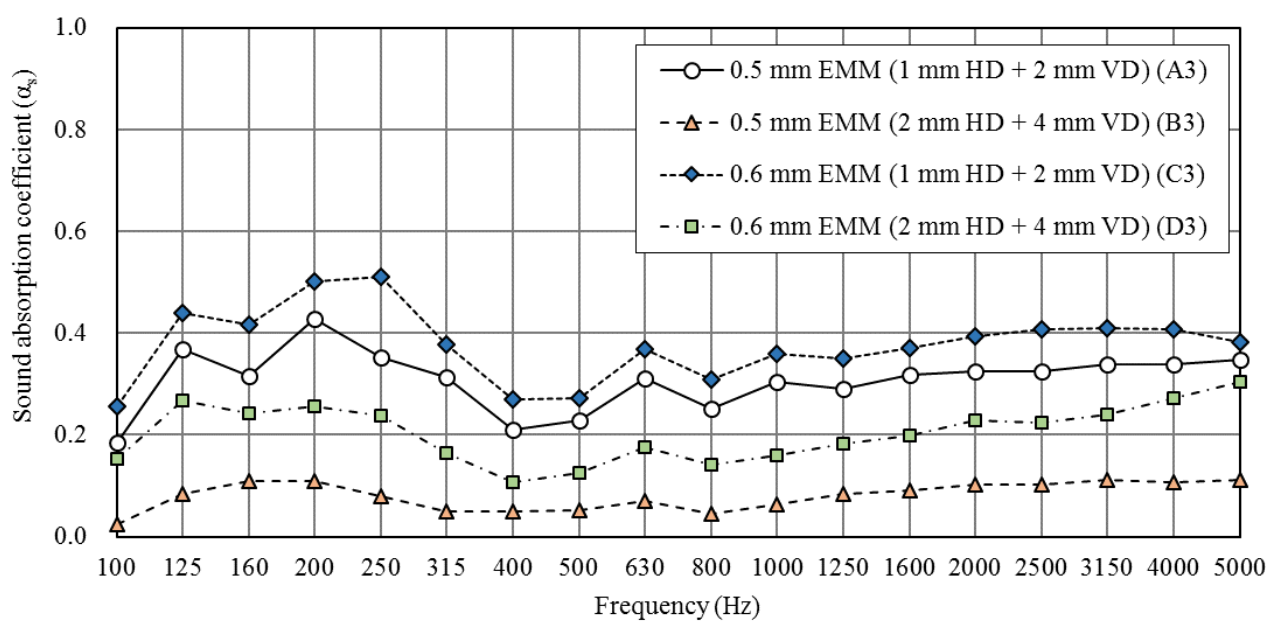

Figure 8. The sound-absorption coefficient of EMM with a $460 \mathrm{~mm}$ cavity.

Therefore, we selected Type C, which had smaller hole distance and a thicker panel, for further development in the second part. 


\subsection{FEMM Development and Prototyping}

As shown in Table 2, we used three types of forms to build the FEMM, which were triangle, square, and trapezoid.

Table 2. The specimen setting and measurement results of folded expanded metal mesh (FEMM).

\begin{tabular}{|c|c|c|c|c|c|}
\hline No. & Folding Shapes & $\begin{array}{c}\text { FEMM } \\
\text { Thickness } \\
\text { (mm) }\end{array}$ & $\begin{array}{l}\text { Cavity } \\
(\mathrm{mm})\end{array}$ & $\begin{array}{c}\text { Total } \\
\text { Thickness } \\
\text { (mm) }\end{array}$ & $\alpha_{w}$ \\
\hline E1 & & \multirow{10}{*}{80} & \multirow{5}{*}{450} & \multirow{5}{*}{530} & 0.80 \\
\hline E2 & & & & & 0.70 \\
\hline E3 & & & & & 0.75 \\
\hline E4 & & & & & 0.80 \\
\hline E5 & & & & & 0.70 \\
\hline E6 & & & \multirow{5}{*}{200} & \multirow{5}{*}{280} & 0.85 \\
\hline E7 & & & & & 0.75 \\
\hline E8 & & & & & 0.80 \\
\hline E9 & & & & & 0.80 \\
\hline E10 & & & & & 0.75 \\
\hline E11 & $\square$ & \multirow{8}{*}{30} & \multirow{4}{*}{450} & \multirow{4}{*}{480} & 0.75 \\
\hline E12 & 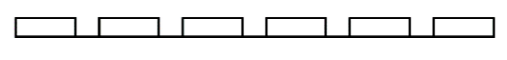 & & & & 0.70 \\
\hline E13 & 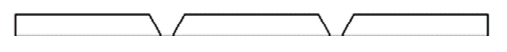 & & & & 0.75 \\
\hline E14 & $\square \neg \neg \neg \neg r$ & & & & 0.65 \\
\hline E15 & $\square$ & & \multirow{4}{*}{200} & \multirow{4}{*}{230} & 0.85 \\
\hline E16 & 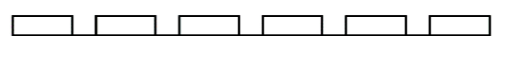 & & & & 0.85 \\
\hline E17 & 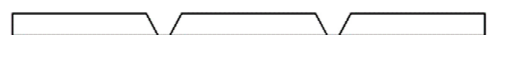 & & & & 0.80 \\
\hline E18 & 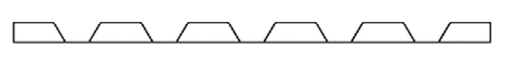 & & & & 0.70 \\
\hline E19 & 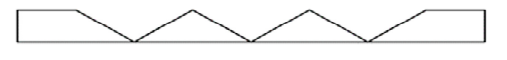 & \multirow{6}{*}{55} & \multirow{6}{*}{450} & \multirow{6}{*}{505} & 0.70 \\
\hline E20 & $\square$ & & & & 0.70 \\
\hline E21 & \begin{tabular}{|l|l|} 
& \\
\end{tabular} & & & & 0.75 \\
\hline E22 & $\square \sqcap \square \square \square \square$ & & & & 0.70 \\
\hline E23 & $\square \longdiv { \square }$ & & & & 0.80 \\
\hline E24 & 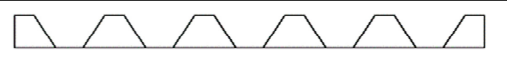 & & & & 0.65 \\
\hline
\end{tabular}


Table 2. Cont.

\begin{tabular}{cccccc}
\hline No. & Folding Shapes & $\begin{array}{c}\text { FEMM } \\
\text { Thickness } \\
(\mathbf{m m})\end{array}$ & $\begin{array}{c}\text { Cavity } \\
(\mathbf{m m})\end{array}$ & $\begin{array}{c}\text { Total } \\
\text { Thickness } \\
(\mathbf{m m})\end{array}$ & $\alpha_{w}$ \\
\hline $\mathrm{E} 25$ & & 200 & 0.70 \\
\hline $\mathrm{E} 29$ & & & 255 & 0.75 \\
\hline $\mathrm{E} 30$ & & & & 0.85 \\
\hline
\end{tabular}

As a whole, regardless of the panel curve, the results showed that the sound-absorption coefficient had the same trend under the same height of the specimen, as shown in Figures 9-14. The $\alpha_{w}$ of the specimen with a $200 \mathrm{~mm}$ cavity was better than that with a $450 \mathrm{~mm}$ cavity. Moreover, the $30 \mathrm{~mm}$ height of the specimen with a $200 \mathrm{~mm}$ cavity achieved high sound-absorption performance $\left(\alpha_{w} \geq 0.8\right)$.

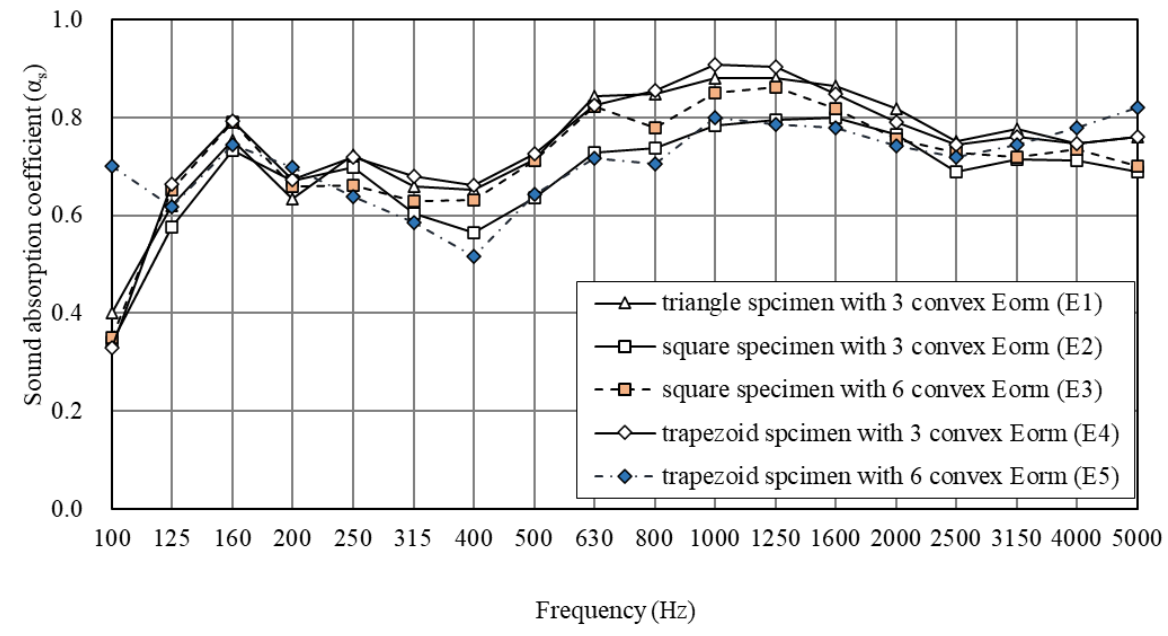

Figure 9. The sound-absorption coefficient of $80 \mathrm{~mm}$ FEMM with a $450 \mathrm{~mm}$ cavity.

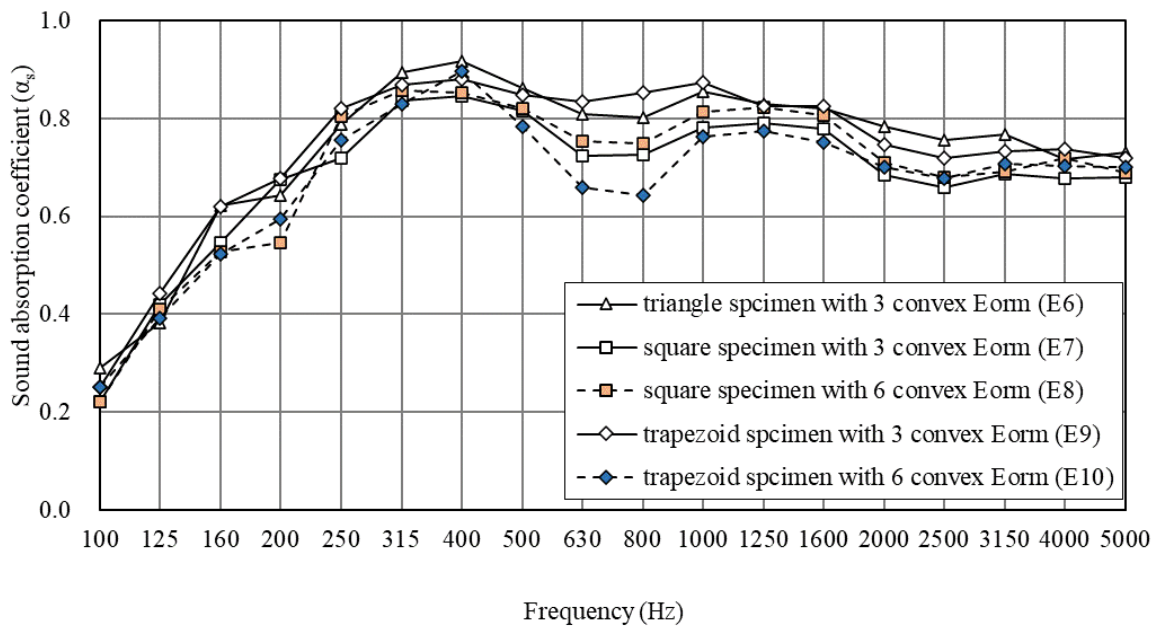

Figure 10. The sound-absorption coefficient of $80 \mathrm{~mm}$ FEMM with a $200 \mathrm{~mm}$ cavity. 


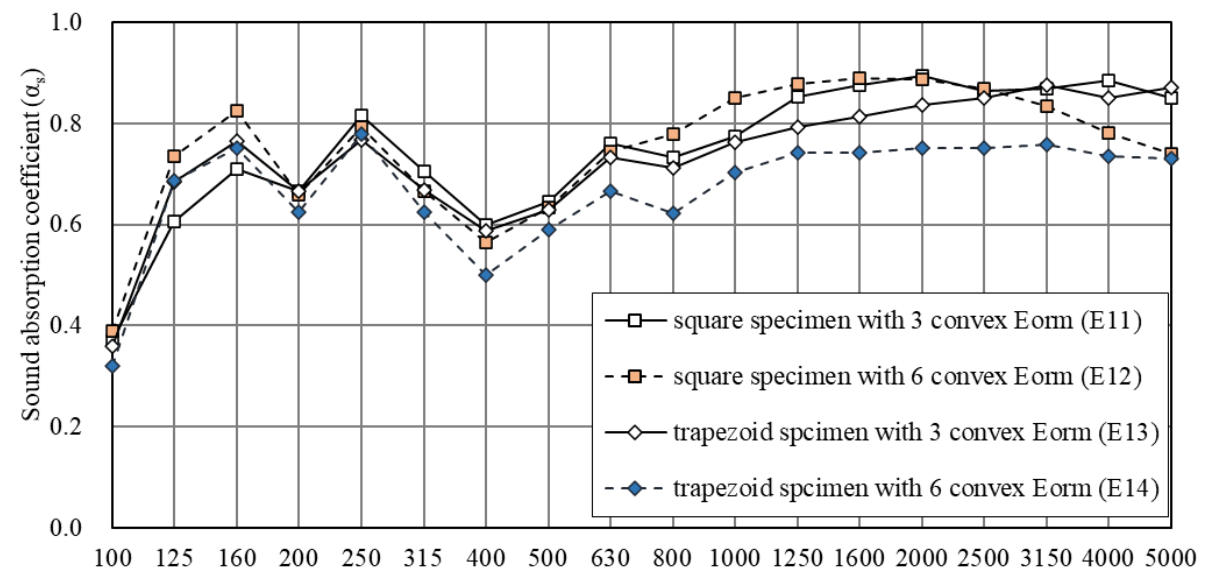

Frequency $(\mathrm{Hz})$

Figure 11. The sound-absorption coefficient of $30 \mathrm{~mm}$ FEMM with a $450 \mathrm{~mm}$ cavity.

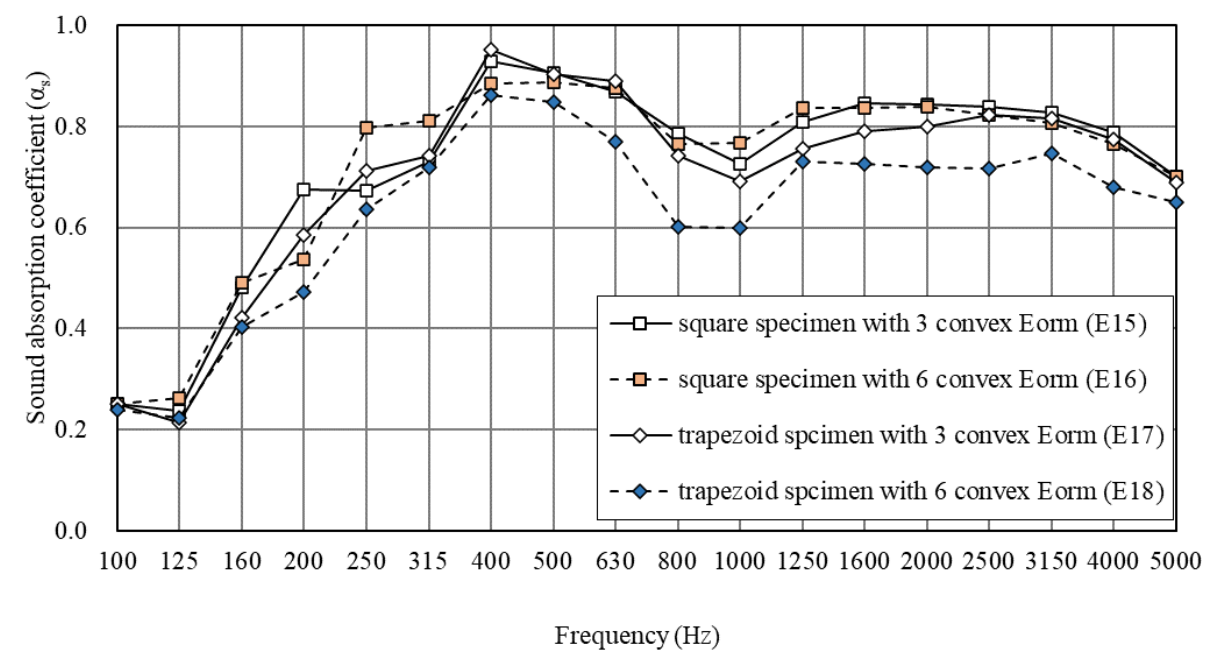

Figure 12. The sound-absorption coefficient of $30 \mathrm{~mm}$ FEMM with a $200 \mathrm{~mm}$ cavity.

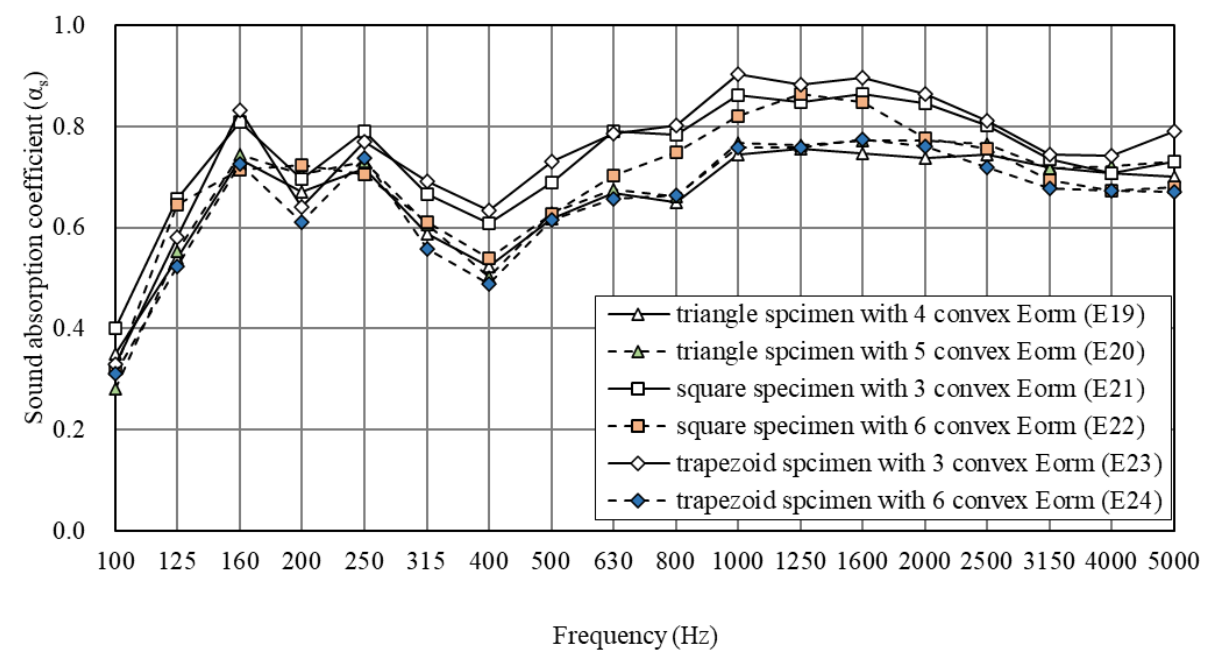

Figure 13. The sound-absorption coefficient of $55 \mathrm{~mm}$ FEMM with a $450 \mathrm{~mm}$ cavity. 


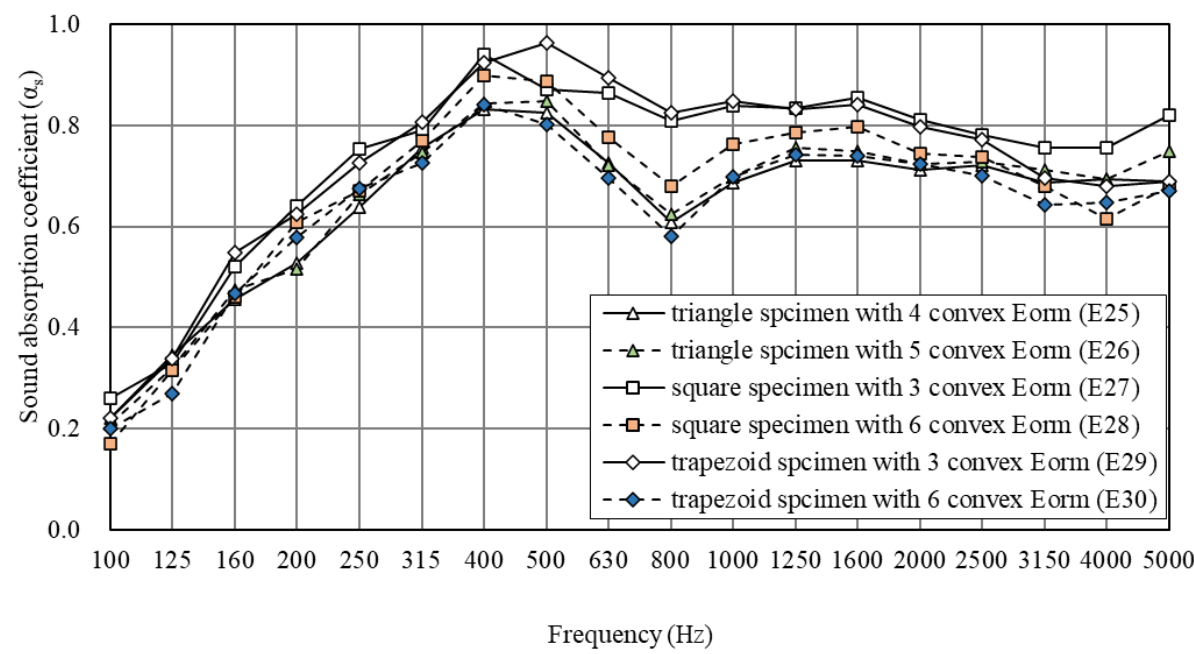

Figure 14. The sound-absorption coefficient of $55 \mathrm{~mm}$ FEMM with a $200 \mathrm{~mm}$ cavity.

As shown in Table 2, among FEMM, E6, E15, E16, and E27 had the greatest soundabsorption performance, and most of those had a rectangular structure. Regarding the trapezoidal structures, those with six convex forms (E5, E10, E14, E18, E24, and E30) had poor sound-absorption performance. Meanwhile, the trapezoidal structures with three convex forms (E4, E9, E17, E23, and E29) all achieved $\alpha_{w} \geq 0.8$, except for E13. Using the trapezoidal concept to fold specimens, low material costs can be selected to achieve better sound-absorption performance.

As described above, folding EMM has less impact on sound-absorption performance than changing the size of the cavity, but a folding structure improved the strength of the specimen.

\section{Field Validation of FEMM}

\subsection{Field Environment}

This research selected an office room in a university as the study object for field verification. The office is a rectangular room with a light steel joist structure on the ceiling and contained no other materials with sound-absorption properties except curtains, as shown in Figure 15. The volume of the space was $147.3 \mathrm{~m}^{3}$, the ceiling area was $46 \mathrm{~m}^{2}$, the installation area was $22 \mathrm{~m}^{2}$ (61 pieces of the specimen), and the cavity behind the ceiling was $62.5 \mathrm{~cm}$. Since the measuring environment had air conditioning, the noise criterion (NC) was 25 , the temperature was $26.6^{\circ} \mathrm{C}$, and the relative humidity was $51.5 \%$.

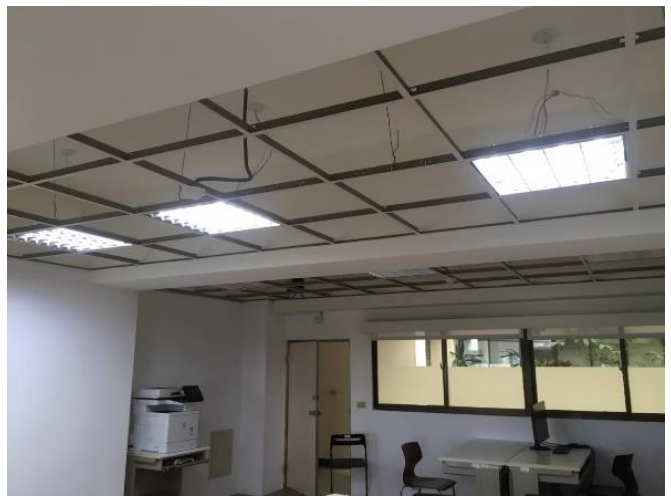

(a)

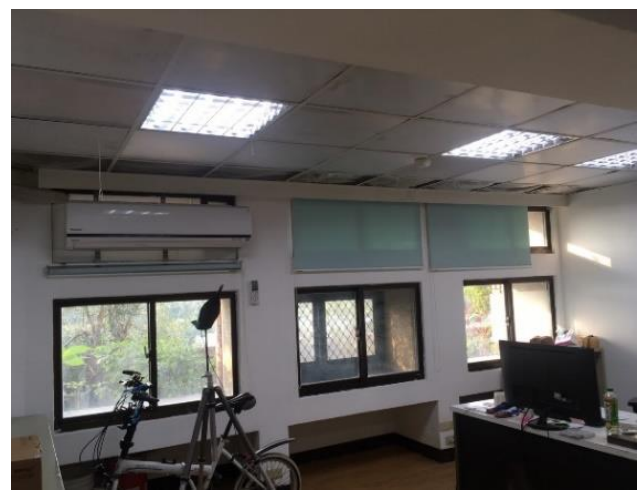

(b)

Figure 15. The field measurement office: (a) before FEMM installation; and (b) after FEMM installation. 


\subsection{Acoustic Index}

Room acoustical parameters are commonly used to evaluate or predict the acoustical performance in rooms. For instance, the distribution of sound energy in a space can be obtained by measuring the sound pressure level (SPL). Furthermore, the comfort and quality of user experience can be obtained through reverberation time (RT) and speech clarity $\left(\mathrm{C}_{50}\right)$.

$\mathrm{RT}$, the time for sound energy to fade away or decay in a closed space, is defined as the time it takes for sound to decay by $60 \mathrm{~dB}$ and was also written as $\mathrm{T}_{60}$. However, accurately measuring $T_{60}$ is difficult. Therefore, it is often common to measure $T_{20}$ and $T_{30}$ and then multiply these by 3 and 2 , respectively, to obtain the overall $\mathrm{T}_{60}$. Speech clarity $\left(C_{50}\right)$ is the ratio of early-to-late arriving sound energy ratio. When $C_{50}>0$, early sound energy dominates the sound field and satisfies basic speech intelligibility. In general, $C_{50}$ has a high relation with RT, where the lower the RT, the better the $C_{50}$. In this paper, these acoustical parameters are introduced and given by Equations (2)-(5).

$$
\begin{aligned}
S P L & =10 \log \left(\frac{p}{p_{0}}\right)^{2} \\
p_{0} & =2 \times 10^{-5}
\end{aligned}
$$

where SPL is the sound pressure level $(\mathrm{dB}) ; p$ the instantaneous sound pressure of the impulse response measured at the measurement point $(\mathrm{Pa})$; and $p_{0}$ is the basic sound pressure $(\mathrm{Pa})$.

$$
T=\frac{0.161 \mathrm{~V}}{S \bar{\alpha}}
$$

where $T$ is the reverberation time (s); $V$ is the volume of the room $\left(\mathrm{m}^{3}\right) ; S$ is the total surface area of the room; and $\bar{\alpha}$ is the average sound-absorption coefficient of materials in the room.

$$
C_{50}=10 \lg \frac{\int_{0}^{50} p^{2}(t) d_{t}}{\int_{50}^{\infty} p^{2}(t) d_{t}} d B
$$

where $C_{50}$ is the early-to-late index $(\mathrm{dB})$; and $p(t)$ is the instantaneous sound pressure of the impulse response measured at the measurement point $(\mathrm{Pa})$.

\subsection{Measurements}

Pursuant to ISO 3382-1 [27] and ISO 3382-2 [28], experiments were carried out before and after the installation of the folding structure. In this study, the sound source was an omnidirectional loudspeaker via Dirac software (Brüel \& Kjær, Nærum, Denmark) that output Maximum Length Sequence (MLS) digital signals and analysis after a 1/2 free-field microphone received the sound power, as shown in Figure 16. In Figure 17, the sound source was set in the center of the office, and all microphone positions were evenly distributed throughout the office (P1-P4). The measured data were the total average of the four points.

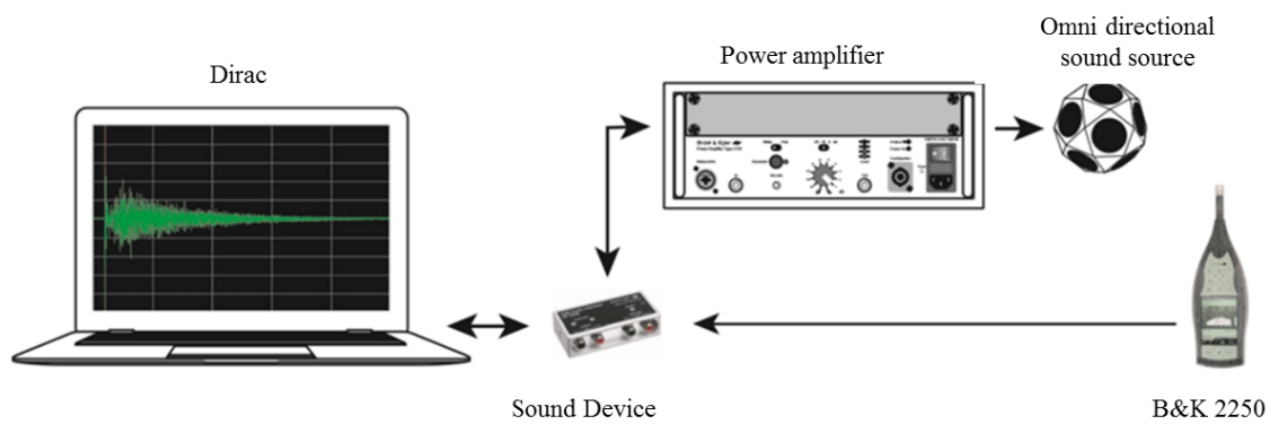

Figure 16. The system of the field measurement. 


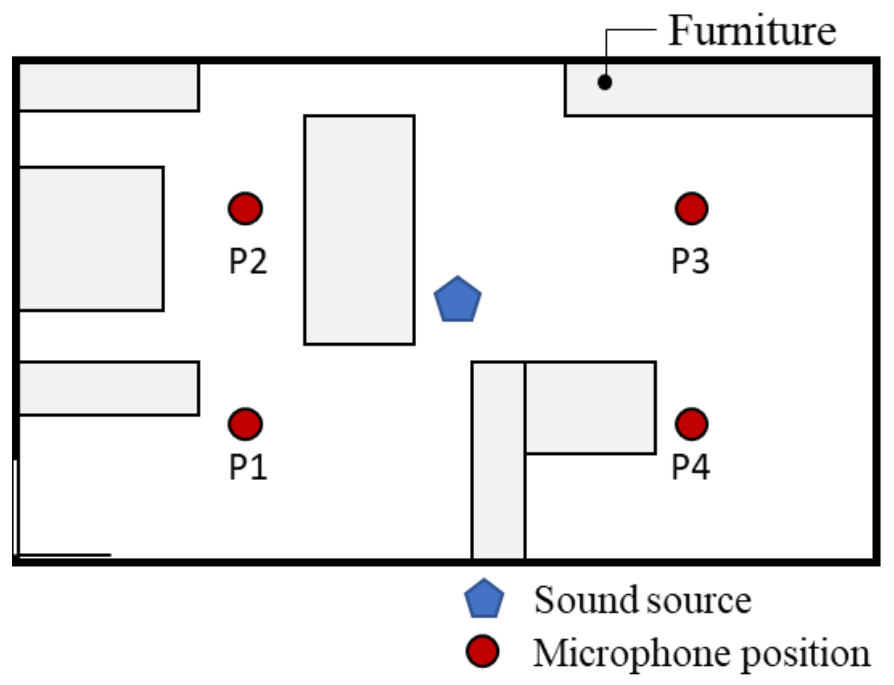

Figure 17. The position of the measurement points.

Figure 18 shows that following the introduction of FEMM, the SPL of each microphone position was reduced by $2.2-3.3 \mathrm{~dB}$ and further demonstrates that the sound energy in the space was evenly distributed.

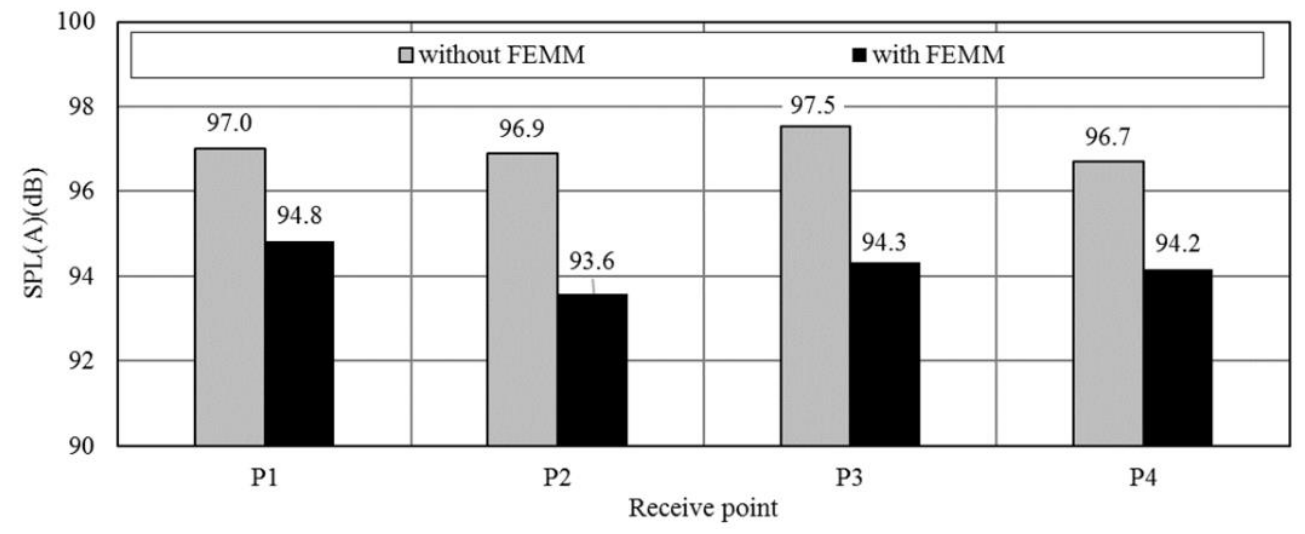

Figure 18. Comparison of the sound pressure level (SPL) at each microphone position.

The RT decreased from $1.05-0.56 \mathrm{~s}$ at $500 \mathrm{~Hz}$ and decreased about $0.25-0.46 \mathrm{~s}$ at all frequencies, as shown in Figure 19.

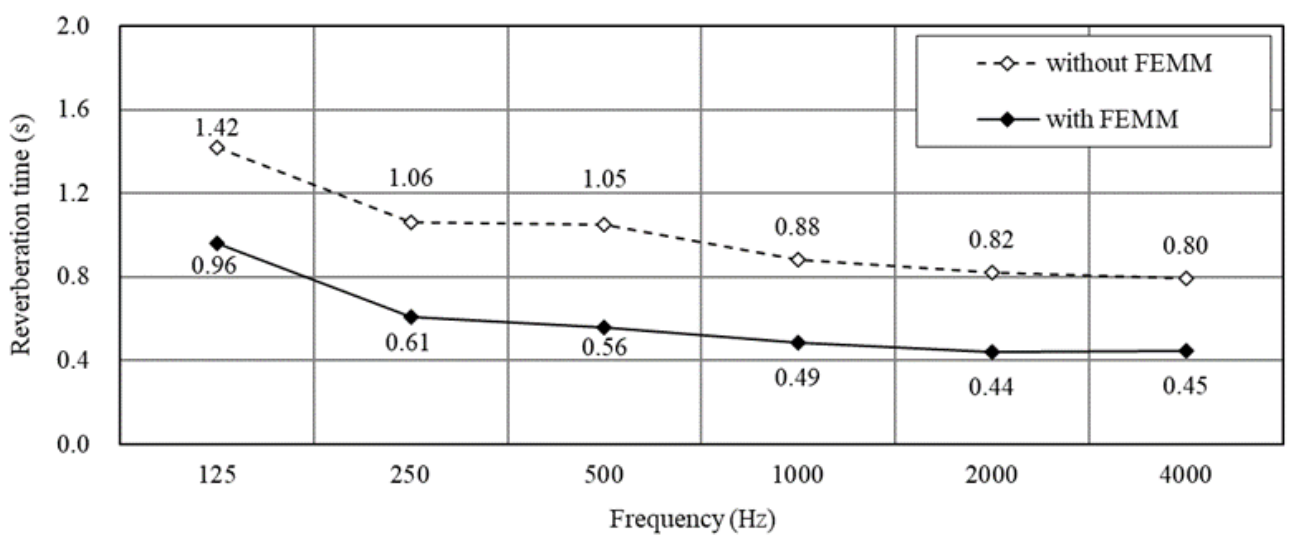

Figure 19. Comparison of the RT at each band. 
As shown in Figure 20, the $C_{50}$ result shows a negative value at $125 \mathrm{~Hz}$ without the FEMM, indicating that the clarity at low frequency was under-performing. Furthermore, the $C_{50}$ increased by $2.6-6.5 \mathrm{~dB}$ at all frequencies after installing the FEMM, indicating that the speech clarity of each frequency achieved better performance.

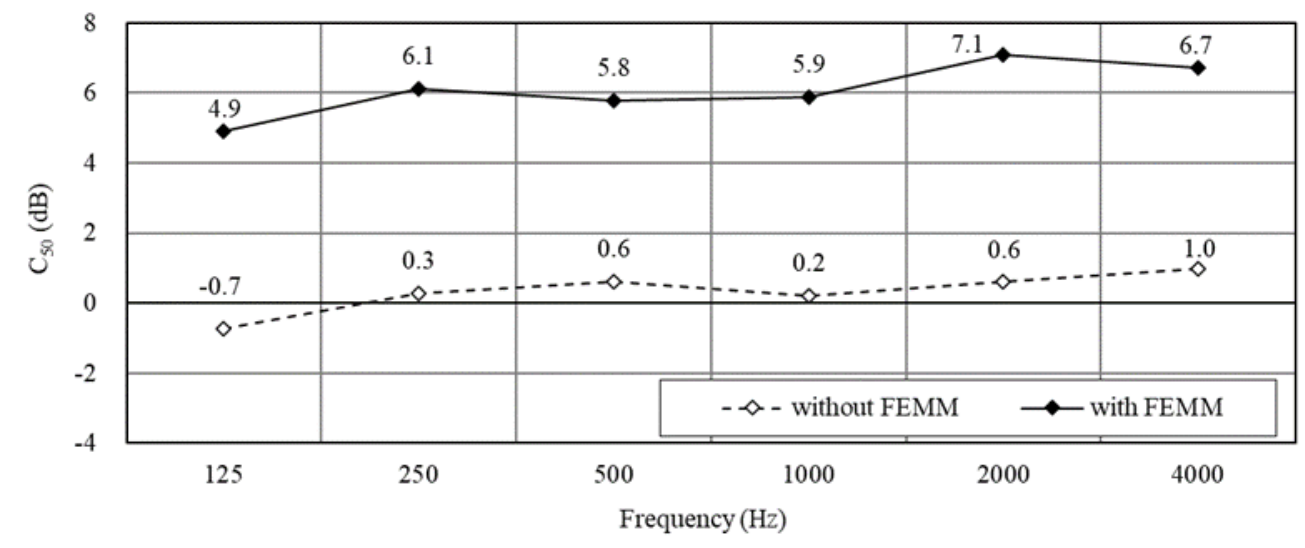

Figure 20. Comparison of speech clarity $\left(C_{50}\right)$ at each band.

\section{Conclusions}

In this research, we develop FEMM prototypes with three different structures and measured the sound-absorption performance to confirm the characteristics of FEMM. Afterward, we selected a specimen with high sound-absorption performance to apply to the field and then discussed the improvement in office acoustics.

The first part of stage 1 shows four types of single-panel EMM that were tested. On the premise that the specimens were not filled with porous sound-absorption materials, the $\alpha_{w}$ of all specimens was lower than 0.35 .

To achieve better sound-absorption performance, we designed a sound-absorption material with a folding structure in three different shapes: triangle, square, and trapezoid, respectively. The results showed that the main factor influencing the octave of sound absorption was the thickness of the cavity. In this part, we carried out 30 measurement results, in which the $\alpha_{w}$ was $0.65-0.85$. Regardless of the folding shape of the FEMM and the cavity thickness, the sound-absorption coefficient was maintained at 0.6-0.9 above $1000 \mathrm{~Hz}$. Finally, the folding shapes did not significantly affect the sound-absorption performance, and the difference in the sound-absorption coefficient was only 0.2 at most at a specific frequency.

The field verification results showed that when the FEMM was installed in the office, which covered about $47.8 \%$ of the ceiling area, the RT was effectively reduced by about $0.25-0.46 \mathrm{~s}$, while the $C_{50}$ improved significantly. The overall results show that FEMM not only has high sound-absorption performance but also provides sound-absorption capability of space and could provide a better acoustics environment.

In the end, comparing the cost of EMM and perforated panel. when perforating a perforated plate, residual material will be generated. The EMM is created with numerous holes through the stretching process, therefore, the cost of the expanded metal mesh is lower than that of the perforated plate.

Author Contributions: Formal analysis, P.-C.T.; Investigation, J.-Y.L.; Methodology, J.-Y.L.; Project administration, Y.-S.T.; Software, P.-C.T.; Writing—original draft, J.-Y.L.; Writing—review \& editing, Y.-S.T. All authors have read and agreed to the published version of the manuscript.

Funding: This research was supported by Ministry of Science and Technology (109-2622-E-006-032).

Institutional Review Board Statement: Not applicable.

Informed Consent Statement: Not applicable. 
Data Availability Statement: The data presented in this study are available upon request from the corresponding author.

Conflicts of Interest: The authors declare no conflict of interest.

\section{References}

1. European Council Directive 67/548/EEC of 27 June 1967. On the approximation of laws, regulations and administrative provisions relating to the classification, packaging and labelling of dangerous substances. Off. J. Eur. Commun. 1967, 196, 1-98.

2. Tao, Y.; Hu, L.H.; Xiong, X.M.; Michal, P.; Noman, M.; Mishra, R.; Jiri, M. Sound Absorption Properties of Natural Fibers: A Review. Sustainability 2020, 12, 8477. [CrossRef]

3. Kaarlela-Tuomaala, A.; Helenius, R.; Keskinen, E.; Hongisto, V. Effects of acoustic environment on work in private office rooms and open-plan offices-Longitudinal study during relocation. Ergonomics 2009, 52, 1423-1444. [CrossRef]

4. Rachel, L.M.; Roy, K.S. Open plan office space? If you're going to do it, do it right: A fourteen-month longitudinal case study. Appl. Ergon. 2020, 82, 102933. [CrossRef]

5. Passero, C.R.M.; Zannin, P.H.T. Acoustic evaluation and adjustment of an open-plan office through architectural design and noise control. Appl. Ergon. 2012, 43, 1066-1071. [CrossRef]

6. Hodgson, M. Experimental investigation of the acoustical characteristics of university classrooms. Acoust. Soc. Am. 1999, 106, 1810. [CrossRef]

7. Kłosak, A.K. Design, simulations and experimental research in the process of development of sound absorbing perforated ceiling tile. Appl. Acoust. 2020, 161, 107185. [CrossRef]

8. McGarrigle, R.; Kevin, J.M.; Dawes, P.; Andrew, J.S.; David, R.M.; Johanna, G.B.; Amitay, S. Listening effort and fatigue: What exactly are we measuring? A British society of audiology cognition in hearing special interest group 'white paper'. Int. J. Audiol. 2014, 53, 433-445. [CrossRef]

9. Ricciardia, P.; Buratti, C. Environmental quality of university classrooms: Subjective and objective evaluation of the thermal, acoustic, and lighting comfort conditions. Build. Environ. 2018, 127, 23-36. [CrossRef]

10. Liu, K.H.; Lai, R.P.; Kuo, C.H. A study on the sound-absorbing characteristics of multi air layer. Appl. Mech. Mater. 2013, 420, 92-98. [CrossRef]

11. Liu, K.H. A Research on Sound Absorption Coefficient Prediction Model of Metal Plate Structure. Ph.D. Thesis, National Cheng Kung University, Tainan, Taiwan, 2014.

12. Liu, Z.; Zhan, J.; Fard, M.; Davy, J.L. Acoustic properties of multilayer sound absorbers with a 3D printed micro-perforated panel. Appl. Acoust. 2017, 121, 25-32. [CrossRef]

13. Wang, J.; Rubini, P.; Qin, Q. Application of a porous media model for the acoustic damping of perforated plate absorbers. Appl. Acoust. 2017, 127, 324-335. [CrossRef]

14. Peng, F. Sound absorption of a porous material with a perforated facing at high sound pressure levels. Sound Vib. 2018, 425, 1-20. [CrossRef]

15. Maa, D.Y. Design of microperforated panel constructions. Inst. Acoust. Chin. Acad. Sci. 1988, 13, 174-180.

16. Meng, H.; Galland, M.A.; Ichchou, M.; Bareille, O.; Xin, F.X.; Lu, T.J. Small perforations in corrugated sandwich panel significantly enhance low frequency sound absorption and transmission loss. Compos. Struct. 2017, 182, 1-11. [CrossRef]

17. Jung, S.S.; Kim, Y.T.; Lee, D.H.; Kim, H.C.; Cho, S.I.; Lee, J.K. Sound absorption of micro-perforated panel. Korean Phys. Soc. 2007, 50, 1044-1051. [CrossRef]

18. Yu, X.; Fang, H.; Cui, F.; Cheng, L.; Lu, Z. Origami-inspired foldable sound barrier designs. Sound Vib. 2019, 442, 514-526. [CrossRef]

19. Wang, D.W.; Wen, Z.H.; Glorieux, C.; Ma, L. Sound absorption of face-centered cubic sandwich structure with micro-perforations. Mater. Des. 2020, 186, 108344. [CrossRef]

20. Guo, W.; Min, H. A compound micro-perforated panel sound absorber with partitioned cavities of different depths. Energy Procedia 2015, 78, 1617-1622. [CrossRef]

21. Tan, W.H.; Afendi, M.; Ahmad, R.; Daud, R.; Shukry, M.; Cheng, E.M. Sound absorption analysis on micro-perforated panel sound absorber with multiple size air cavities. Mech. Mechatron. Eng. 2015, 15, 71-76.

22. Huang, S.; Li, S.; Wang, X.; Mao, D. Micro-perforated absorbers with incompletely partitioned cavities. Appl. Acoust. 2017, 126, 114-119. [CrossRef]

23. Sakagami, K.; Morimoto, M.; Yairi, M. Application of microperforated panel absorbers to room interior surfaces. Acoust. Vib. 2008, 13, 120-124.

24. Toyoda, M.; Sakagami, K.; Takahashi, D.; Morimoto, M. Effect of a honeycomb on the sound absorption characteristics of panel-type absorbers. Appl. Acoust. 2011, 72, 943-948. [CrossRef]

25. ISO 354. Acoustics-Measurement of Sound Absorption in a Reverberation Room; ISO: Geneva, Switzerland, 2003.

26. ISO 11654. Acoustics—Sound Absorbers for Use in Buildings—Rating of Sound Absorption; ISO: Geneva, Switzerland, 1997.

27. ISO 3382-1. Acoustics-Measurement of Room Acoustic Parameters_Part 1: Performance Spaces; ISO: Geneva, Switzerland, 2009.

28. ISO 3382-2. Acoustics-Measurement of Room Acoustic Parameters-Part 2: Reverberation Time in Ordinary Rooms; ISO: Geneva, Switzerland, 2008. 